\title{
Fenomenologia de Merleau-Ponty na produção stricto sensu da enfermagem brasileira: estudo documental
}

\author{
Merleau-Ponty phenomenology in the stricto sensu production of brazilian nursing: documental study
}

Fenomenología de Merleau-Ponty en la producción stricto sensu de enfermería brasileña: estudio documental

\author{
Bruno Neves da Silva ${ }^{1}$; Érika Simone Galvão Pinto ${ }^{2}$; Mel Matos de Carvalho \\ ESPINHEIRA $^{3}$; QUEUAM FERREIRA SILVA DE OLIVEIRA ${ }^{4}$; GILBERTO TADEU REIS DA SILVA ${ }^{5}$ \\ UNIVERSIDAdE FEDERAL do RIO GRANDE do NORTE, UFRN, NATAL-RN, BRASIL \\ Escola Bahiana de Medicina e Saúde Pública, EBMSP, Salvador-BA, Brasil \\ Universidade Estadual de FeIra de Santana, UEFS, FeIra de Santana-BA, Brasil \\ UNIVERSIDADE FEDERAL DA BAHIA, UFBA, SALVADOR-BA, BRASIL
}

\begin{abstract}
RESUMO
O presente estudo objetivou documentar a produção stricto sensu da enfermagem brasileira que utilizou o referencial fenomenológico de Merleau-Ponty. Método: estudo documental, com abordagem quantitativa, realizado mediante análise dos relatórios de pesquisa indexados no Catálogo de Dissertações e Teses da Coordenação de Aperfeiçoamento de Pessoal de Nível Superior. Foram utilizadas estatísticas descritivas, análise de similitude e nuvens de palavras para análise dos dados. Resultados: 98 relatórios de pesquisa compuseram a amostra. Os termos enfermagem, fenomenologia, cuidados de enfermagem, percepção, existencialismo, espiritualidade, família, adolescente e saúde da mulher representaram temáticas relevantes relacionadas aos estudos. Discussão: A fenomenologia reforça a condição indissociável entre a pessoa em suas diversas dimensões e a singularidade de suas inter-relações diante de cada fenômeno. Considerações finais: A fenomenologia de Merleau-Ponty reitera a horizontalidade desta base teórica e sua inter-relação com a integralidade do ser.
\end{abstract}

Palavras-chave: Enfermagem. Filosofia em Enfermagem. Educação de Pós-Graduação em Enfermagem.

\begin{abstract}
This study aimed to document the stricto sensu production of Brazilian nursing that used the phenomenological framework of Merleau-Ponty. Method: documentary study, with a quantitative approach, carried out through analysis of research reports indexed in the Catalog of Dissertations and Theses of the Coordination for the Improvement of Higher Education Personnel. Descriptive statistics, similarity analysis and word clouds were used for data analysis. Results: 98 research reports comprised the sample. The terms nursing, phenomenology, nursing care, perception, existentialism, spirituality, family, adolescent and women's health represented relevant themes related to the studies. Discussion: Phenomenology reinforces the inseparable condition between people in their different dimensions and the uniqueness of their interrelationships in face of each phenomenon. Considerations: Merleau-Ponty's phenomenology reiterates the horizontality of this theoretical basis and its interrelationship with the integrality of being.
\end{abstract}

Keywords: Nursing. Philosophy in Nursing. Graduate Nursing Education.

\section{RESUMEN}

Este estudio tuvo como objetivo documentar la producción stricto sensu de la enfermería brasileña que utilizó el marco fenomenológico de Merleau-Ponty. Método: estudio documental, con enfoque cuantitativo, realizado a través del análisis de informes de investigación indexados en el Catálogo de Disertaciones y Tesis de la Coordinación para la Perfeccionamiento del Personal de Educación Superior. Se utilizó estadística descriptiva, análisis de similitud y nubes de palabras para el análisis de datos. Resultados: 98 informes de investigación componen la muestra. Los términos enfermería, fenomenología, cuidados de enfermería, percepción, existencialismo, espiritualidad, familia, salud del adolescente y de la mujer representaron temas relevantes relacionados con los estudios. Discusión: La fenomenología refuerza la condición inseparable de las personas en sus diferentes dimensiones y la singularidad de sus interrelaciones frente a cada fenómeno. Consideraciones finales: La fenomenología de Merleau-Ponty reitera la horizontalidad de esta base teórica y su interrelación con la integralidad del ser.

Palabras clave: Enfermería. Filosofía en Enfermería. Educación de Posgrado en Enfermería.

\footnotetext{
1 Doutorando em Enfermagem na Atenção à Saúde pela UFRN. E-mail: enfbneves@gmail.com. ORCID: https://orcid.org/0000-0001-9854-4492.

Docente do Programa de Pós-Graduação em Enfermagem da UFRN. E-mail: erikasgp@gmail.com. ORCID: https://orcid.org/0000-0003-0205-6633.

${ }^{3}$ Mestra em Tecnologias da Saúde pela EBMSP. E-mail: mel.espinheira@ gmail.com. ORCID: https://orcid.org/0000-00023938-4465.

${ }^{4}$ Mestra em Enfermagem pela UEFS. E-mail: queuam@hotmail.com. ORCID: https://orcid.org/0000-0002-3347-4339.

${ }^{5}$ Professor Titular da UFBA. E-mail: gilberto.tadeu@ ufba.br. ORCID: https://orcid.org/0000-0002-0595-0780.
} 


\section{INTRODUÇ̃̃O}

$\mathrm{Na}$ pesquisa qualitativa, o conceito de realidade é multifacetado e subjetivo. As experiências individuais e percepções dos sujeitos são aspectos importantes, uma vez que, por meio delas, a realidade é construída conjuntamente entre pesquisado e pesquisador. Assim, considerando que as visões de realidade, valores e os conhecimentos tendem a ser distintos em cada abordagem metodológica, as diferentes percepções acerca do fenômeno estudado e da realidade demandam, frequentemente, a utilização de diversos métodos pelos pesquisadores (PATIAS; HOHENDORFF, 2019).

O enfoque qualitativo não visa opor-se aos outros enfoques, colocando-se, apenas, como uma possibilidade de investigação, tendo como objeto de atenção os fenômenos, da maneira como se mostram nas descrições das experiências vividas, no pré-reflexivo e em diferentes perspectivas (ESPÓSITO, 2021). A adoção deste paradigma torna-se cada vez mais frequente no âmbito da enfermagem, como uma forma de explorar os fenômenos relacionados ao cuidado, e de propiciar informações científicas ao campo disciplinar, entendendo o relacionamento entre enfermeiro e cliente como uma relação subjetiva, suscetível de ser estudada pela fenomenologia (GONZÁLEZ-SOTO; MENEZES; GUERREROCASTAÑEDA, 2021).

A pesquisa de cunho fenomenológico representa uma proposta de investigação do cotidiano da pessoa que permite ir além do mundo dos conhecimentos teóricos e das aparências. Possibilita aproximação da experiência humana sob novas nuances com vistas a apreendê-la a partir de sua dimensão existencial, que se anuncia velada. Dessa forma, buscase apreender a condição ontológica do ser humano que está existindo em uma experiência mundana, atribuindo-lhe significados (GRAÇAS, 2000).

A fenomenologia, de maneira geral, movimenta-se no sentido de uma investigação e descrição direta dos fenômenos (entendidos como qualquer coisa que se faça presente à consciência), que são experienciados conscientemente, livre de teorias sobre suas explicações causais. Tal investigação deve ser tão isenta quanto possível de pressuposições e preconceitos, a fim de favorecer a apreensão de suas estruturas, movimentos e formas (ESPÓSITO, 2021).

Dentre os referenciais utilizados nas pesquisas de cunho fenomenológico, destacam-se teóricos como Edmund Husserl, Martin Heidegger, Alfred Schütz, Paul Ricoer, Maurice Merleau-Ponty, dentre outros. Neste estudo, a concepção privilegiada de fenomenologia adotada foi a de Merleau-Ponty, que considera a consciência como percepção. Para este filósofo, não há separação ou oposição no ato de apreensão das coisas, entre os dados racionais e os dados sensíveis, pois nossas experiências constituem a fonte de todo o conhecimento, que é adquirido no mundo que existe ao nosso redor, e que só passa a existir efetivamente quando lhe atribuímos um sentido. Logo, a consciência está a todo momento voltando-se para o mundo, e buscando, através da essência, um contato mais íntimo e direto com a existência (com o próprio mundo) (MERIGHI; PRAÇA, 2003).

Ainda segundo Merleau-Ponty (2013), essa percepção se relaciona com a atitude corpórea, e a apreensão dos sentidos se realiza pelo corpo, que é o campo criador dos sentidos, um acontecimento da corporeidade A existência, para Merleau-Ponty, ocorre no corpo-próprio, e realizar a existência total implica afirmar que o corpo não é um meio utilizado pela existência para exteriorizá-la, mas sim, encarnado; é o corpo pleno de desejos que, ao viver suas experiências afetivas, dá vazão à existência (BICUDO, 2000).

$\mathrm{O}$ estudo dos fenômenos relacionados ao cuidado de enfermagem deve apoiar-se na compreensão dos sentimentos e pensamentos das pessoas perante o continuum saúde-doença que a própria existência supõe. Nesse sentido, o referencial de Merleau-Ponty se destaca na enfermagem pelo caráter subjetivo da essência humana, que possibilita acessar as experiências mais íntimas e menos exploradas de ser cuidador e de ser cuidado, assim como 
sua mútua interação (GONZÁLEZ-SOTO; MENEZES; GUERRERO-CASTAÑEDA, 2021). Ademais, na medida em que busca os significados das experiências vivenciadas, a pesquisa fenomenológica vai ao encontro da enfermagem, pois coopera para a busca da compreensão do homem, sujeito do cuidado (MERIGHI; PRAÇA, 2003).

Diante do exposto, o presente estudo objetivou documentar a produção stricto sensu da enfermagem brasileira que utilizou o referencial fenomenológico de Merleau-Ponty. Destaca-se a relevância de compreender esse panorama para evidenciar a contribuição do referido referencial filosófico no planejamento e construção de práticas de cuidados, o que pode contribuir para torná-lo mais holístico e congruente às necessidades dos indivíduos. Buscou-se responder ao questionamento norteador: como se caracteriza a produção stricto sensu da enfermagem brasileira que utilizou o referencial fenomenológico de Maurice Merleau-Ponty?

\section{Metodologia}

Trata-se de um estudo documental com abordagem quantitativa, realizado por meio de consultas aos relatórios de pesquisa indexados no Catálogo de Dissertações e Teses da Coordenação de Aperfeiçoamento de Pessoal de Nível Superior (CAPES).

A coleta de dados ocorreu em setembro de 2021, utilizando-se as palavras-chave "Fenomenologia" e "Merleau-Ponty", isoladas, sem combinações. Não foi estabelecido recorte temporal na coleta dos dados e foram aplicados os filtros "Grau acadêmico" (mestrado, mestrado profissional e doutorado) e "Área de conhecimento" (enfermagem).

Constituíram critérios de inclusão: relatórios de pesquisa (teses e dissertações) disponíveis integralmente, ou passíveis de serem recuperados em repositórios institucionais; da área de enfermagem; e que versassem sobre a fenomenologia. Foram excluídos da amostra os estudos que abordassem o referencial fenomenológico ancorado em outro filósofo que não Maurice Merleau-Ponty.

Finalizadas as buscas iniciais, os estudos que compuseram a amostra foram selecionados mediante leitura atenta dos títulos, resumos e leitura flutuante do texto completo. Posteriormente à etapa de seleção, criou-se um banco de dados utilizando-se do software Microsoft Excel $2016^{\circledR}$ para processamento estatístico descritivo das variáveis extraídas dos relatórios de pesquisa: grau acadêmico, ano de defesa, região e Instituição de Ensino Superior (IES). Os resultados foram apresentados por meio da utilização de figuras.

Para análise exploratória dos temas dos estudos, prosseguiu-se com a extração das palavras-chave de cada relatório de pesquisa, criando-se um arquivo textual importado para processamento estatístico textual pelo software Interface de $R$ pour les Analyses Multidimensionnelles de Textes et de Questionnaires (IRAMUTEQ ${ }^{\circledR}$ ), no qual foram conduzidas análises de similitude e construção de nuvem de palavras.

Quanto aos preceitos éticos, este estudo dispensou apreciação por Comitê de Ética em Pesquisa por utilizar dados de domínio livre, conforme os pressupostos da Resolução 510/2016 do Conselho Nacional de Saúde.

\section{RESUltados}

A inserção dos termos-chave na base de dados elencada proporcionou um número inicial de 6.179 relatórios de pesquisa. Após aplicação dos filtros de busca, este quantitativo diminuiu para 532 teses e dissertações. Destas, 35 não foram localizadas, restando 497 estudos, dos quais 446 foram selecionados mediante leitura dos títulos. Após leitura atenta 
dos resumos, leitura flutuante dos estudos na íntegra e exclusão das publicações duplicadas em cada busca, 98 relatórios de pesquisa compuseram a amostra, conforme pode ser visualizado na figura 1.

Figura 1: Esquematização dos passos para composição da amostra do estudo.

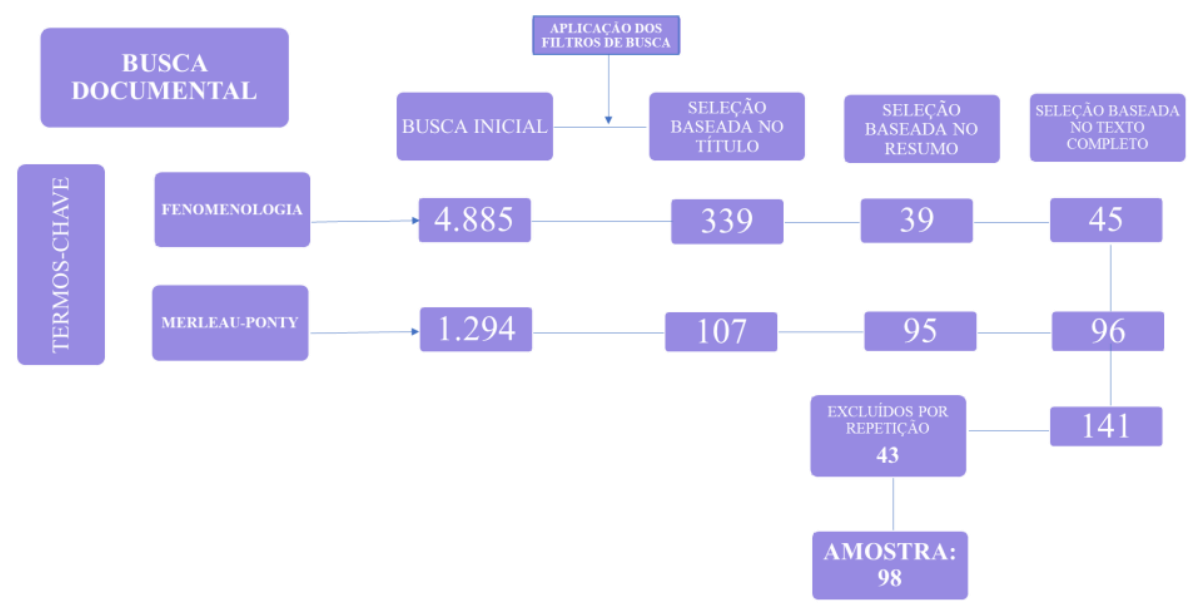

Fonte: dados da pesquisa.

Quanto ao nível acadêmico, 63,3\% $(\mathrm{n}=62)$ dos relatórios de pesquisa corresponderam a dissertações de mestrado, enquanto as teses de doutorado representaram 27,5\% ( $\mathrm{n}=27)$, e as dissertações provenientes de mestrados profissionais, 9,2\% $(n=9)$ da amostra. O intervalo temporal de publicação dos estudos apontou maior número de produções no ano de 2018 , sendo a primeira produção utilizando o referencial abordado detectada no ano de 1992, conforme é possível observar na série histórica a seguir.

Figura 2: Distribuição das dissertações e teses conforme ano de publicação.

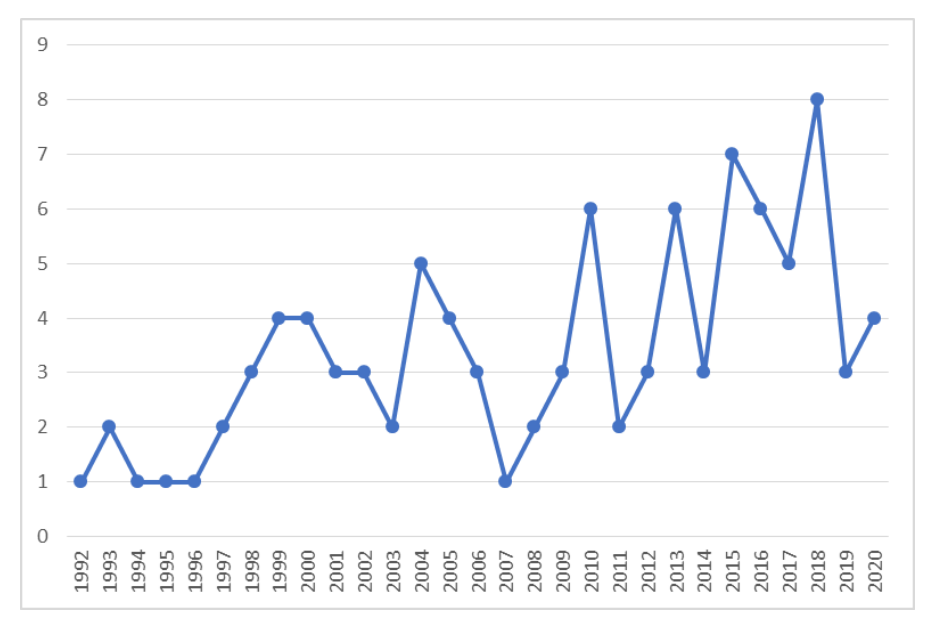

Fonte: dados da pesquisa.

No que concerne à região do país em que os estudos foram desenvolvidos, constatouse predominância na Região Sudeste, seguida pelas Regiões Sul e Nordeste. Não foram identificados estudos produzidos na Região Norte do país. Observou-se, ainda, predomínio de estudos desenvolvidos em determinadas IES, com destaque para a Universidade Federal Fluminense (UFF), Universidade Estadual do Sudoeste da Bahia (UESB), Universidade de 
Bruno N. da Silva; Érika S. G. Pinto; Mel M. C. Espinheira; Queuam F. S. de Oliveira; Gilberto T. R. da Silva

São Paulo (USP) e Universidade Federal de Santa Catarina (UFSC). A distribuição dos estudos conforme região do país e IES vinculada se encontra representada na figura 3.

Figura 3: Distribuição dos estudos conforme Região do Brasil e Instituição de Ensino Superior vinculada.
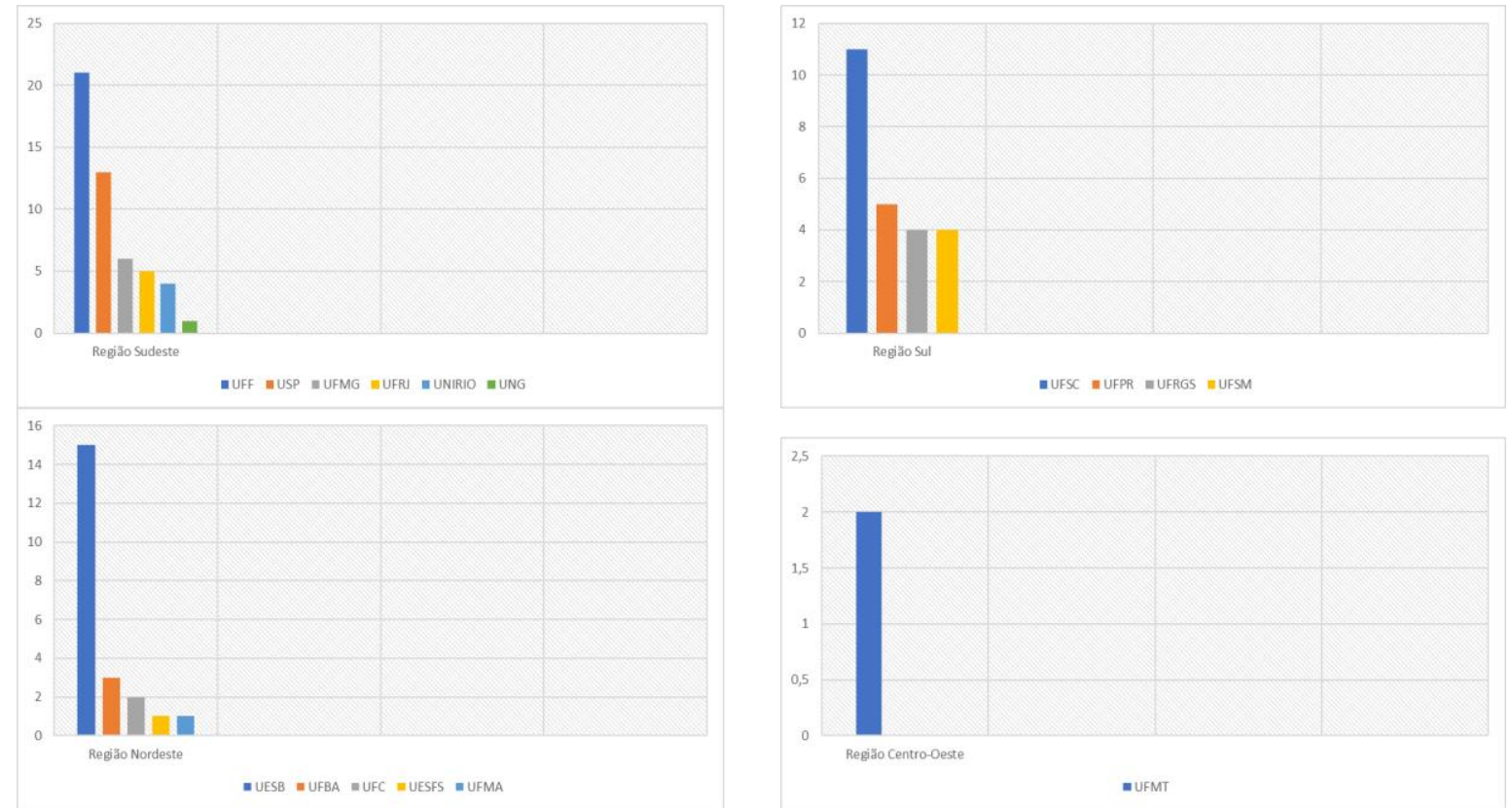

Fonte: dados da pesquisa.

Em relação à análise exploratória dos temas dos estudos realizada com auxílio do IRAMUTEQ $^{\circledR}$, a figura 4 apresenta a nuvem de palavras elaborada mediante a extração das palavras-chave dos estudos que compuseram a amostra. Na medida em que as palavras com maior tamanho foram aquelas que apareceram com maior frequência nos estudos, destaca-se que, além dos termos enfermagem, fenomenologia e filosofia em enfermagem, cuidados de enfermagem, percepção, existencialismo, espiritualidade, família e adolescente foram temáticas relevantes relacionadas aos estudos.

Figura 4: Nuvem de palavras composta a partir das palavras-chave extraídas dos estudos que compuseram a amostra.

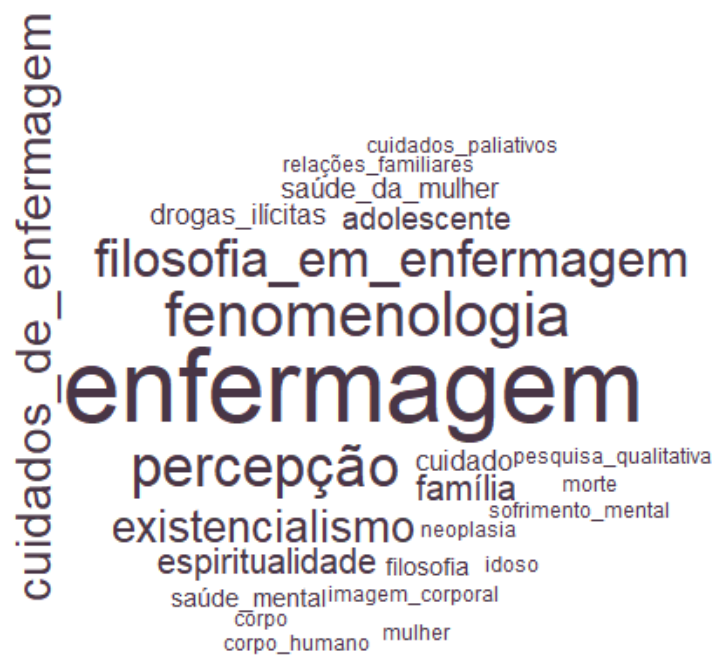

Fonte: dados da pesquisa. 
Por fim, no intuito de evidenciar as conexões que as temáticas abordadas tiveram entre si, utilizou-se a análise de similitude, que se baseia na teoria dos grafos e permite visualizar as conexões entre as palavras (mais fortes conforme mais grossas as arestas que as interligam). A seguir, na figura 5, nota-se que as pesquisas se ancoraram na palavra-chave enfermagem, área-mãe dos estudos, da qual partiram ramificações centrais para as palavras existencialismo e fenomenologia, as quais estabeleceram outras ramificações.

A palavra-chave filosofia em enfermagem, por sua vez, possui conexão menos evidenciada com as palavras anteriores, porém relações fortes com família, saúde mental, idoso e drogas ilícitas.

Figura 5: Análise de similitude do corpus textual.

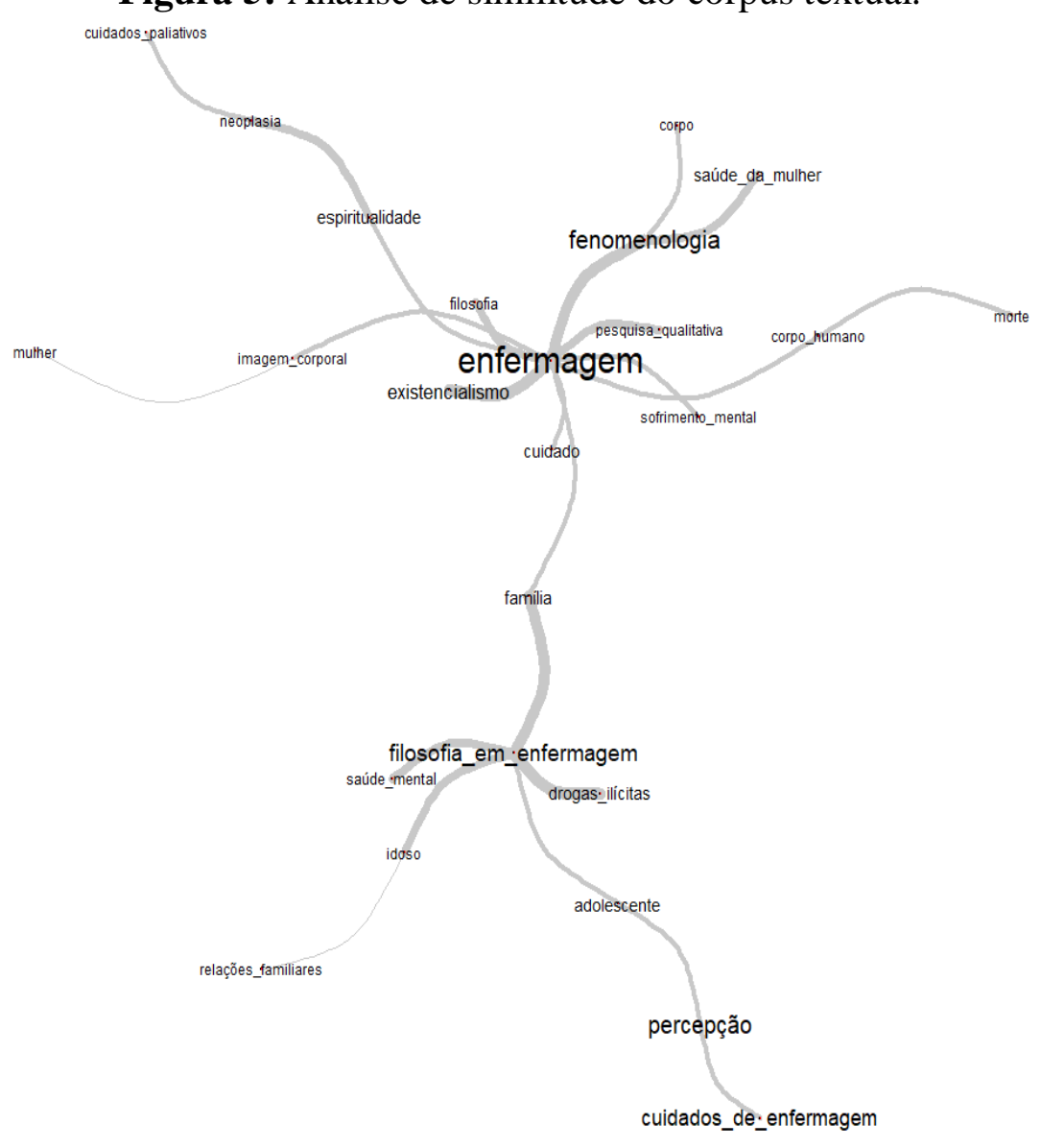

Fonte: dados da pesquisa.

\section{DisCUSSÃo}

$\mathrm{Na}$ amostra eleita para o estudo, observou-se a presença majoritária da abordagem acerca do tema nas dissertações de mestrado, seguida das teses de doutorado e dissertações de mestrado profissional. $\mathrm{O}$ ano de 2018 despontou como o de maior recorrência na produção científica nesse contexto. Infere-se que esses resultados possam estar relacionados com a realização de eventos sobre o tema nesse período, a exemplo do Congresso Internacional de Merleau-Ponty, promovido pelo Departamento de Filosofia da Universidade de São Paulo.

O predomínio das Regiões Sudeste, Sul e Nordeste, por sua vez, partilha com o observado na literatura e pode ser atribuído ao maior número de pesquisadores que estudam a temática nessas regiões (ANTONINI et al. 2014). 
Em relação ao termo existencialismo, acredita-se que possa ter aparecido nos estudos pelo fato de ser um descritor controlado, diferentemente do termo fenomenologia. $\mathrm{O}$ existencialismo humano tem reflexos nas condições de vida e direcionamento cotidiano e, nesse sentido, os estudos encontrados trazem similaridade e aproximação aos termos que podem expressar reflexões acerca da vida e condição existencial do ser. Através da fenomenologia, a enfermagem tem contribuído com reflexões sobre os significados das experiências vividas, sobretudo da importância do cuidado para o outro (HENRIQUES; BOTELHO; CATARINO, 2021).

É na fenomenologia que se reforça a condição indissociável entre a pessoa em suas diversas dimensões, bem como a singularidade de suas relações e inter-relações diante de cada fenômeno. A fenomenologia de Merleau-Ponty, em especial, enfatiza o conceito de estar no mundo, compreendendo a experiência do mundo vivido e sua expressão através do corpo (MERLEAU-PONTY, 2013).

Ressalta-se que as temáticas representadas pelas palavras-chave podem ter sido abordadas sob a perspectiva de Merleau-Ponty por suas conexões com o tema da corporeidade. Isso porque é nesse corpo que a percepção deste filósofo se encontra fundada, na experiência do sujeito encarnado, que sente e que olha, e que, na experiência de corpo fenomenal, reconhece o espaço como simbólico e expressivo (NÓBREGA, 2008).

O corpo, dessa forma, carrega a transcendência e as experiências sensoriais, constituindo-se do "fundo" perceptivo em relação ao qual as coisas se oferecem (CAMARGO, 2020). O autor rompe com as noções clássicas de órgãos do sentido como receptores passivos, ao afirmar que as sensações ocorrem associadas a movimentos. Para ele, cada objeto induz à realização de um gesto, e não há representação, e sim criação, novas maneiras de interpretar diferentes situações existenciais (NÓBREGA, 2008).

$\mathrm{Na}$ obra Fenomenologia da Percepção, Merleau-Ponty assume como problema principal a compreensão das relações entre a alma e o corpo. Dessa forma, busca compreender a articulação entre o fisiológico e o psicológico, de modo a dirimir prejuízos da Filosofia clássica e da Psicologia e Fisiologia modernas, principalmente a compreensão da experiência humana com base no dualismo sujeito-objeto (CAMARGO, 2020).

Merleau-Ponty não reduz o corpo às suas características psicofisiológicas, como frequentemente abordado pela ciência convencional inspirada no cartesianismo, sugerindo suas diversas relações com a história e a cultura. O filósofo, ao abordar a fisiologia mecanicista e o conceito de corpo como objeto, destaca situações nas quais a doença se mostra na existência de um sujeito, e de como ela tem sido vista como circunstâncias apenas físicas pelos padrões da ciência tradicional. Posteriormente, Merleau-Ponty discute que a noção de corporeidade e existência é prejudicada pela dicotomia entre físico e psíquico, uma vez que é na existência que esses aspectos se integram (SOUZA; ERDMANN, 2006).

No âmbito da enfermagem, as contribuições da filosofia de Merleau-Ponty permitem reconhecer o fato de que os seres humanos não se constituem simplesmente de corpos divididos pelos limites de uma ciência que os fragmentam e os fazem perder a essência. Sob essa perspectiva, somos destacados como seres integrados em uma totalidade, desafiados a exercitar inúmeras possibilidades pelo mundo no qual estamos imersos, e nos constituímos de corpo no espaço e no tempo, livres em situação e eminentemente expressivos, e, consequentemente, comunicativos, sensíveis, interativos (SOUZA; ERDMANN, 2006).

Nesse sentido, as experiências vividas se refletem, sobretudo, na estrutura universal e comportamental do humano, e compreendê-la em sua totalidade permite uma aproximação da verdadeira singularidade da essência evidente para cada pessoa. A dimensão fenomenológica do cuidado favorece a compreensão dos significados de cada experiência vivida por cada pessoa, e tal percepção, por sua vez, contribui para a reflexão do processo do viver e de suas diversas interações (GONZÁLEZ-SOTO; MENEZES; GUERRERO-CASTAÑEDA, 2021). 
A prática de enfermagem, cuja ação volta-se ao cuidado, assume o holismo e o corpo físico para as dimensões do cuidar (THOMAS, 2018). Ao retratar as práticas em enfermagem, nota-se a importância da relação cuidador-cuidado, uma vez que os profissionais cuidadores também interagem com um meio e realidade, os quais, por conseguinte, interferem e correlacionam-se com o outro, sujeito de cuidados. Essa dinâmica reforça o quanto as vivências de mundo permitem relações com outras pessoas e, profissionalmente, podem ter reflexos na prestação de cuidados de enfermagem (VALDERRAMA; ARCE, 2018).

É através de sua existência que o ser humano pode ser compreendido. Suas experiências vividas possibilitam a exploração do vivido, e estas reflexões contribuem para o cuidado em enfermagem direcionado de um modo significativamente singular às reais perspectivas de cada pessoa (HENRIQUES; BOTELHO; CATARINO, 2021).

No que se refere aos outros eixos representados pelas palavras-chave e suas conexões, termos como espiritualidade, família, adolescente, drogas ilícitas, saúde da mulher, dentre outros, expressam um contexto de associação à multidimensionalidade humana. Além disso, permitem refletir acerca do contexto histórico na enfermagem, o que envolve desde o processo de formação em enfermagem como as ações no cotidiano em saúde que se aproximam de uma análise existencial.

Dessa maneira, a abordagem fenomenológica de Merleau-Ponty pode auxiliar na compreensão das tantas dimensões da enfermagem, uma vez que as várias temáticas abordadas pelo filósofo permitem uma aproximação de fenômenos como a saúde e a doença, no sentido de favorecer a expressão dos sujeitos que os vivenciam enquanto dimensões do existir. Enfermagem e Filosofia (em especial a Merleau-pontyana), dessa forma, são companheiras, que se entrelaçam e ampliam a dinâmica da construção do conhecimento, fundamentando as possibilidades de um pensar que não subtrai a existência e o ser enquanto se faz, mas ampliam a oportunidade do pensar-fazer-pensar? (SOUZA; ERDMANN, 2006).

\section{CONSIDERAÇõES FINAIS}

A fundamentação teórica fenomenológica de Merleau-Ponty, ainda que tímida na produção stricto sensu, está presente em diversos estudos que abordam a enfermagem brasileira. Destaca-se sua concentração nas Regiões Sul, Sudeste e Nordeste do Brasil, sendo pouco difundida no Centro-Oeste, não sendo localizados registros de produção na Região Norte do país. Contudo, tal fundamentação permite compreender a horizontalidade desta base teórica, bem como sua inter-relação com a integralidade do ser.

A fenomenologia de Merleau-Ponty possibilita a integração do ser humano em suas diversas contextualizações. Assim, os estudos que discutem enfermagem e fenomenologia desvelam um contexto multidimensional do ser e permitem compreensão da essência do conceito de cuidar, uma vez que, por meio dessas análises, o existencialismo humano pode ser direcionado a partir de sua singularidade e percursos de vida. Desse modo, estudar os fenômenos que estão relacionados ao cuidar em enfermagem favorece uma interação e reflexão intersubjetiva da essência humana, bem como o desenvolvimento de práticas individuais e mais próximas das reais necessidades de cada pessoa.

Estudos sobre a realização de práticas assistenciais nos mais diversos espaços de trabalho e tecnologias, tal como análises acerca do processo formativo em enfermagem e reflexões do cuidar nos mais diversos ciclos de vida, possibilitam o entendimento multidirecional do cuidado em enfermagem, principalmente por permitirem integrar corpo e ambiente. Dessa forma, devem ser impulsionados, e a fenomenologia de Maurice-MerleauPonty se constitui em um referencial adequado para tanto. 
Bruno N. da Silva; Érika S. G. Pinto; Mel M. C. Espinheira; Queuam F. S. de Oliveira; Gilberto T. R. da Silva

\section{REFERÊNCIAS}

ANTONINI, F. O.; BOEHS, A. E.; LENARDT, M. H.; BUDÓ, M. L. D.; MONTICELLI, M. Enfermagem e cultura: características das teses e dissertações produzidas na pós-graduação da enfermagem brasileira. Revista de Enfermagem da UFSM, v. 4, n. 1, p. 163-171, 2014. Disponível em: https://doi.org/10.5902/217976929724. Acesso em: 01 nov. 2021.

BICUDO, M. A. V. Fenomenologia: confrontos e avanços. São Paulo: Cortez, 2000.

CAMARGO, J. Sobre as consequências filosóficas do primado da percepção em Merleau-Ponty. Trans/Form/Ação, Marília, v. 43, p. 231-256, 2020. Disponível em: https://doi.org/10.1590/01013173.2020.v43esp.17.p231. Acesso em: 01 nov. 2021.

ESPÓSITO, V. H. C. Pesquisa qualitativa de natureza fenomenológica e hermenêutica em educação: trajetórias. Motricidades: Revista da SPQMH, v. 5, n. 2, p. 225-234, 2021. Disponível em: https://doi.org/10.29181/25946463-2021-v5-n2-p225-234. Acesso em: 01 nov. 2021.

GONZÁLEZ-SOTO, C. E.; MENEZES; T. M. O.; GUERRERO-CASTAÑEDA R. F. Reflexión sobre la fenomenología de Merleau-Ponty y sus aportes a la investigación de enfermeira. Revista Gaúcha de Enfermagem, v. 42, e20190439, 2021. Disponível em: https://doi.org/10.1590/1983-1447.2021.20190439. Acesso em: 01 nov. 2021.

GRAÇAS, E. M. Pesquisa qualitativa e a perspectiva fenomenológica: fundamentos que norteiam sua trajetória. Revista Mineira de Enfermagem, v. 4, n. 1-2, p. 28-33, 2000. Disponível em: https://cdn.publisher.gn1.link/reme.org.br/pdf/v4n1a06.pdf. Acesso em: 04 nov. 2021.

HENRIQUES, C. M. G.; BOTELHO, M. A. R.; CATARINO, H. C. P. A fenomenologia como método aplicado à ciência de enfermagem: estudo de investigação. Ciência \& Saúde Coletiva, v. 26, n. 2, p. 511-519, 2021. Disponível em: https://doi.org/10.1590/1413-81232021262.41042020. Acesso em: 01 nov. 2021.

MERIGHI, M. A. B.; PRAÇA, N. S. Abordagens teórico-metodológicas qualitativas: vivências da mulher no período reprodutivo. Rio de Janeiro: Guanabara Koogan: 2003.

MELEAU-PONTY, M. Fenomenologia da percepção. 2. ed. São Paulo: Martins Fontes, 1999.

NÓBREGA, T. P. Corpo, percepção e conhecimento em Merleau-Ponty. Estudos de Psicologia, v. 13, n. 2, p. 141-148, 2008. Disponível em: https://doi.org/10.1590/S1413-294X2008000200006. Acesso em: 01 nov. 2021.

PATIAS, N. D.; HOHENDORFF, J. V. Critérios de qualidade para artigos de pesquisa qualitativa. Psicologia em Estudo, v. 24, e43536, 2019. Disponível em: https://doi.org/10.4025/psicolestud.v24i0.43536. Acesso em: 01 nov. 2021.

SOUZA, A. I. J; ERDMANN, A. L. Contribuições para o conhecimento em enfermagem à luz da fenomenologia da percepção de Merleau-Ponty. Revista Gaúcha de Enfermagem, v. 27, n. 2, p. 166-175, 2006. Disponível em: https://www.seer.ufrgs.br/rgenf/article/view/4593. Acesso em: 01 nov. 2021.

THOMAS, S. P. Finding inspiration from the philosophy of Maurice Merleau-Ponty for the practice of psychiatric-mental health nursing. Archives of Psychiatric Nursing, v. 32, n. 3, p. 373-378, 2018. Disponível em: https://doi.org/10.1016/j.apnu.2017.11.029. Acesso em: 01 nov. 2021.

VALDERRAMA O.; ARCE, G. Aportes de la Fenomenología Heideggeriana al Cuidado Enfermero.

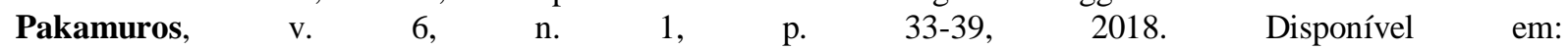
http://revistas.unj.edu.pe/index.php/pakamuros/article/view/57/58. Acesso em: 01 nov. 2021.

Recebido em: 01 nov. 2021.

Aprovado em: 21 dez. 2021.

Motricidades: Rev. SPQMH, v. 5, n. 3, p. 308-316, set.-dez. 2021 | ISSN 2594-6463 |

DOI: http://dx.doi.org/10.29181/2594-6463-2021-v5-n3-p308-316 